\title{
OPEN Two new Russula species (fungi) from dry dipterocarp forest in Thailand suggest niche specialization to this habitat type
}

\begin{abstract}
Komsit Wisitrassameewong ${ }^{1}$, Cathrin Manz ${ }^{2}$, Felix Hampe ${ }^{3}$, Brian P. Looney ${ }^{4}$, Thitiya Boonpratuang $^{1}$, Annemieke Verbeken ${ }^{5}$, Tuksaporn Thummarukcharoen ${ }^{1}$, Tanakorn Apichitnaranon ${ }^{1}$, Maneerat Pobkwamsuk ${ }^{1}$, Miroslav Caboň ${ }^{6}$ \& Slavomír Adamčík ${ }^{6}$

Dry dipterocarp forests are among the most common habitat types in Thailand. Russulaceae are known as common ectomycorrhizal symbionts of Dipterocarpaceae trees in this type of habitat. The present study aims to identify collections of Russula subsection Amoeninae Buyck from dry dipterocarp forests in Thailand. A multi-locus phylogenetic analysis placed Thai Amoeninae collections in two novel lineages, and they are described here as $R$. bellissima sp. nov. and $R$. luteonana sp. nov. The closest identified relatives of both species were sequestrate species suggesting that they may belong to drought-adapted lineages. An analysis of publicly available ITS sequences in $R$. subsect. Amoeninae did not confirm evidence of any of the new species occurring in other Asian regions, indicating that dry dipterocarp forests might harbor a novel community of ectomycorrhizal fungi. Macromorphological characters are variable and are not totally reliable for distinguishing the new species from other previously described Asian Amoeninae species. Both new species are defined by a combination of differentiated micromorphological characteristics in spore ornamentation, hymenial cystidia and hyphal terminations in the pileipellis. The new Amoeninae species may correspond to some Russula species collected for consumption in Thailand, and the detailed description of the new species can be used for better identification of edible species and food safety in the region.
\end{abstract}

Russula Pers. is a genus of ectomycorrhizal agarics and truffles (Basidiomycota) distributed globally. It can be found in diverse forest ecosystems, ranging from the arctic to the tropics. Russula is currently classified into 8 subgenera: Russula subg. Archaea Buyck \& V. Hofst., R. subg. Brevipedum Buyck \& V. Hofst., R. subg. Compactae (Fr.) Bon, R. subg. Crassotunicata Buyck \& V. Hofst., R. subg. Glutinosae Buyck \& X.H. Wang, R. subg. Heterophyllidiae Romagn., $R$. subg. Malodorae Buyck \& V. Hofst., and $R$. subg. Russula ${ }^{1,2}$. Among the most species diverse subgenera, $R$. subg. Heterophyllidia comprises species with diverse basidiocarp colour and microscopic features. Recent multilocus phylogenies have distinguished several well-defined lineages ranked as sections within this subgenus such as R. sect. Aureotactae Buyck \& V. Hofst., R. subsect. Cyanoxanthinae Singer, R. sect. Heterophyllae Fr., R. sect. Ingratae Quél., R. subsect. Ilicinae Buyck., R. subsect. Oleiferinae Buyck and R. sect. Subvelatae Singer ${ }^{1}$.

The diversity of Russula in Thailand is estimated to be high and particularly well represented in broadleaf forests dominated by Dipterocarpaceae or Fagaceae trees ${ }^{3,4}$. Many edible Russula species are gathered in rural regions in northern and northeastern Thailand. However, local mushroom hunters are accustomed to recognizing edible russulas that represent morphological complexes and their identifications to species are unprecise. These field identifications rely on incomplete macromorphological descriptions and even local fungal inventories regularly apply names of American, European or Japanese origin for Thai species ${ }^{5}$. For example, names of the European taxa R. emetica (Schaeff.) Pers. and R. violeipes Quél. were often used for red-capped species ${ }^{5}$, while

\footnotetext{
${ }^{1}$ National Biobank of Thailand, National Science and Technology Development Agency (NSTDA), Thailand Science Park, Khlong Nueng, Khlong Luang, Pathum Thani 12120, Thailand. ${ }^{2}$ Mycology Research Group, Faculty of Biological Sciences, Goethe University Frankfurt am Main, Max-von-Laue Straße 13, 60438 Frankfurt am Main, Germany. ${ }^{3}$ Butzbach, Germany. ${ }^{4}$ Department of Biology, Clark University, Worcester, MA, USA. ${ }^{5}$ Research Group Mycology, Department of Biology, Ghent University, K.L. Ledeganckstraat 35, 9000 Ghent, Belgium. ${ }^{6}$ Plant Science and Biodiversity Centre, Slovak Academy of Sciences, Dúbravská cesta 9, 84523 Bratislava, Slovakia. ${ }^{\circledR}$ email: slavomir.adamcik@savba.sk
} 
current studies have demonstrated that the distributions of European and American taxa are unlikely to extend to southeast Asia. The situation in Asia is more challenging. Some species are apparently distributed in larger areas and even separated by the sea, e.g. R. castanopsidis Hongo known from Japan and Korea ${ }^{6}$ or R. bella Hongo distributed in Japan, Korea and China ${ }^{7}$. Some earlier studies have included a number of Thai collections in ITS phylogenies, but these studies had insufficient sampling of closely related taxa to determine species limits ${ }^{8-10}$. Only a small number of species have been described as new and illustrated in detail from Thailand, and all these reports are relatively new, i.e. R. siamensis Yomyart, Piapukiew, Watling, Whalley \& Sihan ${ }^{11}$, R. aurantiopectinata F. Hampe \& Manz, R. magica Manz \& F. Hampe ${ }^{12}$ and R. purpureogracilis F. Hampe, Looney \& Manz ${ }^{6}$.

This study focuses on Russula diversity of dry dipterocarp forest. Forests dominated by members of the family Dipterocarpaceae are one of the most common and important ecosystems in tropical regions of Asia. They are distributed throughout the Southeast Asian realm, e.g. Malesia, the Mainland Southeast Asia, Indochina Peninsula, South Asia, Sri Lanka and Seychelles Islands ${ }^{13}$. The northernmost distribution of the family in the Indo-Malayan realm is located in subtropical southern China. The dipterocarp tree community of the Indochina Peninsula is specific and different from adjacent areas ${ }^{14}$. The endemicity of Dipterocarpaceae in Asia is relatively high at the extremes of their geographical distribution such as in Sri Lanka, South India, China mainland as well as Malesia, while it is very low in the centre of the Indochina peninsula ${ }^{15}$. Compositions of tree species in forests in northern, northeastern and eastern Thailand are relatively similar ${ }^{16}$. In Thailand, the family Dipterocarpaceae is represented by 8 genera and 63 species $^{17}$ and is distributed in all parts of the country. The majority of species are found in either gallery forests, mixed evergreen or mixed deciduous forests. Only 5 species are xerophytic, which grow on sandy soil in the dry dipterocarp forests; Dipterocarpus obtusiformis, D. tuberculatus, D. intricatus, Shorea obtusa, and S. siamensis. Dry dipterocarp forests in the north and east of the country are widely distributed and frequent forest types along the Indochina Peninsula and are characterized by relatively low precipitation (annual rainfall of 1000-1500 mm), an open canopy and the presence of abundant large herbivores grazing the understory. Core areas of dry dipterocarp forests are located in Myanmar, Thailand, and Cambodia ${ }^{18}$. In northern Thailand, where the relief of the country topography is more rugged, dry dipterocarp forests occur at lower elevation ${ }^{19}$. In the eastern part of the country they also occur in lowlands and low elevations but their occurrence is even more fragmented probably due to intensive human land use $\mathrm{e}^{9,20}$.

This study aims to estimate the diversity of $R$. subsection Amoeninae in dry dipterocarp forests of north and northeast Thailand based on recently collected materials. This subsection is classified in $R$. sect. Heterophyllae and is morphologically characterised by spores with a subreticulate or reticulate ornamentation, the absence of gloeopherous cystidia in the hymenium and pileipellis, and the presence of subulate hyphal terminations both in the pileipellis and on the lamellae edges ${ }^{21}$. Russula subsect. Amoeninae is a well-defined phylogenetic lineage, and, based on publicly available ITS sequence data, it includes at least 30 species worldwide, eight of which are Asian and five have been formally described ${ }^{7}$. In this study, we will specify whether species of Amoeninae found in Thailand match any of the previously described members of the lineage or whether they represent new species.

\section{Results}

Phylogenetic analyses. A total of 21 sequences were newly generated and deposited in GenBank (Supplementary Table 1). The concatenated sequence alignment of the three loci comprised 100 sequences ( 38 for ITS, 30 for $r p b 2$ and 32 for mtSSU) from 43 collections (Supplementary Table 1). The alignment was 2,004 characters long, including gaps. Multi-locus trees generated from ML and BI analyses showed similar topologies without any supported topological conflict. The multi-locus phylogeny (Fig. 1) confirmed placement of all Thai collections within the well-supported $R$. subsect. Amoeninae $(\mathrm{ML}=99, \mathrm{BI}=1.0)$. Five collections from northeastern Thailand and two collections from northern Thailand form two strongly supported clades and are described below as the new species $R$. bellissima sp. nov. and $R$. luteonana sp. nov. The new species are not resolved as sister. The first species, R. bellissima, is strongly supported as sister to a clade of Australian sequestrate species that includes R. variispora T. Lebel and an undescribed Russula sp. labeled as Macowanites sp. The Indian species $R$. intervenosa S. Paloi, A.K. Dutta \& K. Acharya is placed as sister to them with bootstrap support of 77 . The second species, $R$. luteonana, is placed with moderate support as sister to the sequestrate European species $R$. andaluciana T.F. Elliott \& Trappe.

The ITS tree (Fig. 2) shows a similar topology and relationships for the studied specimens. In addition, $R$. intervenosa received good support $(\mathrm{ML}=84, \mathrm{BI}=0.99)$ as sister to the clade of $R$. bellissima and $R$. variispora. Five additional ITS sequences that are grouped with strong support within $R$. bellissima species clade were recovered, three from Thailand, one from Laos, and one from Singapore. We did not recover any other Amoeninae ITS sequences from Thailand.

Taxonomy. Russula bellissima Manz \& F. Hampe sp. nov.. Mycobank: MB 840549. Holotype THAILAND,

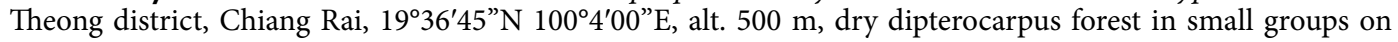
loamy soil, 12 July 2012, F. Hampe (Holotype: GENT FH 12-127; Isotype: MFLU12-0619).

Etymology 'bellus' = latin for beautiful, pretty, lovely; 'bellissima' = the most beautiful. Resembling the species Russula bella which is also belonging to Russula subsection Amoeninae.

Diagnosis Pileus small to medium-sized; cuticle dry, smooth, matt and pruinose, red; stipe white or with a red flush; spore ornamentation of moderately distant to dense amyloid spines or warts, frequently fused into short crests or even long wings; suprahilar spot inamyloid; hymenial cystidia and pileocystidia absent.

Pileus (Fig. 3) small to medium sized, 10-50 mm diam., young hemispherical or convex, becoming plane and depressed at the centre; margin first even, when old distinctly tuberculate-striate up to $10 \mathrm{~mm}$ from the margin, often radially cracking; cuticle hardly peeling, radially disrupted into small patches, pruinose when young, later dry, smooth, matt and pruinose in the centre, colour near the margin when young varnish red (9C8), later red to 


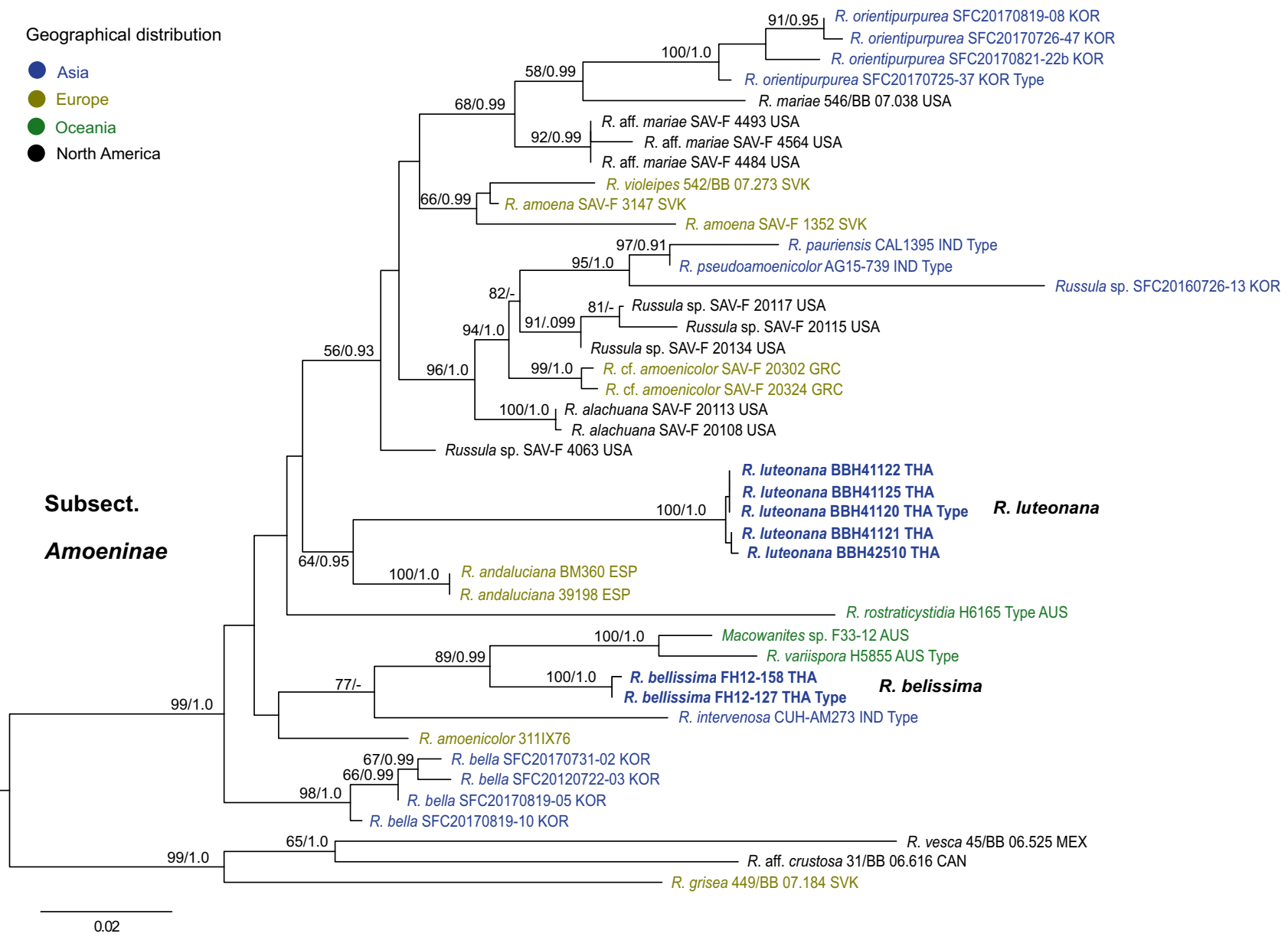

Figure 1. ML phylogenetic tree inferred from the three-gene dataset (ITS, rpb2, mtSSU) of Russula subsection Amoeninae species, using ML and BI analyses. Three members of $R$. subg. Heterophyllidiae are used as outgroup. Species in boldface are new species in this study. Bootstrap support values (BS $\geq 50 \%$ ) and posterior probabilities $(\mathrm{PP} \geq 0.90)$ are shown at the supported branches.

coral red (9B6-7); near the centre deep red, blood red, dark red (10C7-8), raspberry red (10D7), strawberry red (10D8) or purple brown (10E-F8). Lamellae: 3-5 mm deep, thin, moderately dense, $6-8$ at $1 \mathrm{~cm}$ near the pileus margin, adnexed, white, slightly anastomosing at the base; lamellulae absent, occasionally forked near the stipe; edges concolorous, entire but pruinose under lens. Stipe: $10-30 \times 3-7 \mathrm{~mm}$, usually narrowed towards the base, sometimes cylindrical, surface smooth, white and mainly with a distinct pastel red to red flush, occasionally completely white or sometimes also almost completely red, interior stuffed. Context: white, fragile, unchanging when damaged, reaction with guaiac after $5 \mathrm{~s}$ negative on both stipe and lamellae surfaces, reaction to $\mathrm{FeSO}_{4}$ and sulfovanillin negative; taste mild; odour inconspicuous. Spore print: not observed.

Spores (Figs. 4, 5) (6.9-)7.3-7.8-8.3(-8.9) ×(6.1-)6.8-7.2-7.6(-8.4) $\mu \mathrm{m}$, subglobose to broadly ellipsoid, $\mathrm{Q}=1.01-1.1-1.2(-1.29)$; ornamentation of moderately distant $[(4-) 5-6(-7)$ in a $3 \mu \mathrm{m}$ diam. circle] amyloid spines or warts, (1.1-)1.2-1.4-1.6(-1.7) $\mu \mathrm{m}$ high, fused or connected by fine line connections into often long crests or wings, $[(0-) 1-3(-4)$ fusions and the same number of line connections in a $3 \mu \mathrm{m}$ diam. circle], crests and wings frequently branched and occasionally form closed loops, isolated elements dispersed, edge of crests and wings irregularly wavy; suprahilar spot moderately large, inamyloid. Basidia: (30.5-)34.5-44.1-53.5(-65.0 )$\times(10.5-) 11.5-12.6-14.0(-16.0) \mu \mathrm{m}$, broadly clavate or obpyriform, 4-spored; basidiola cylindrical, ellipsoid or broadly clavate, ca. 5-10 $\mu \mathrm{m}$ wide. Hymenial cystidia on lamellae sides: absent. Lamellae edges: covered by densely arranged or fasciculate marginal cells. Marginal cells: $(27.0-) 38.5-\underline{46.4}-54.5(-61.0) \times(5.0-) 5.5-\underline{6.7}-7.5(-9.0) \mu \mathrm{m}$; subulate or narrowly lageniform, apically attenuated and constricted to ca. $1-2 \mu \mathrm{m}$, sometimes slightly moniliform or flexuous. Pileipellis: (Fig. 6) orthochromatic in Cresyl Blue, gradually passing to the underlying context, 200-300 $\mu \mathrm{m}$ deep; suprapellis 60-130 $\mu \mathrm{m}$ deep, composed of erect or ascending hyphal terminations forming a dry trichoderm, well delimited from 140 to $210 \mu \mathrm{m}$ deep subpellis composed of horizontally oriented, strongly gelatinized narrow hyphae. Subpellis not well delimited from the underlying context, elongate hyphae gradually changing to sphaerocytes. Acid-resistant incrustations: absent. Hyphal terminations near the pileus margin: composed of long apically attenuated terminal cell and a chain of 1-4 ovoid to barrel shaped, short unbranched cells with one distinctly longer apical cell; constricted on septa, usually not flexuous, oriented towards the pileus surface, usually thin-walled, sometimes slightly thick-walled (up to $1 \mu \mathrm{m}$ thick); terminal cells mainly subulate 


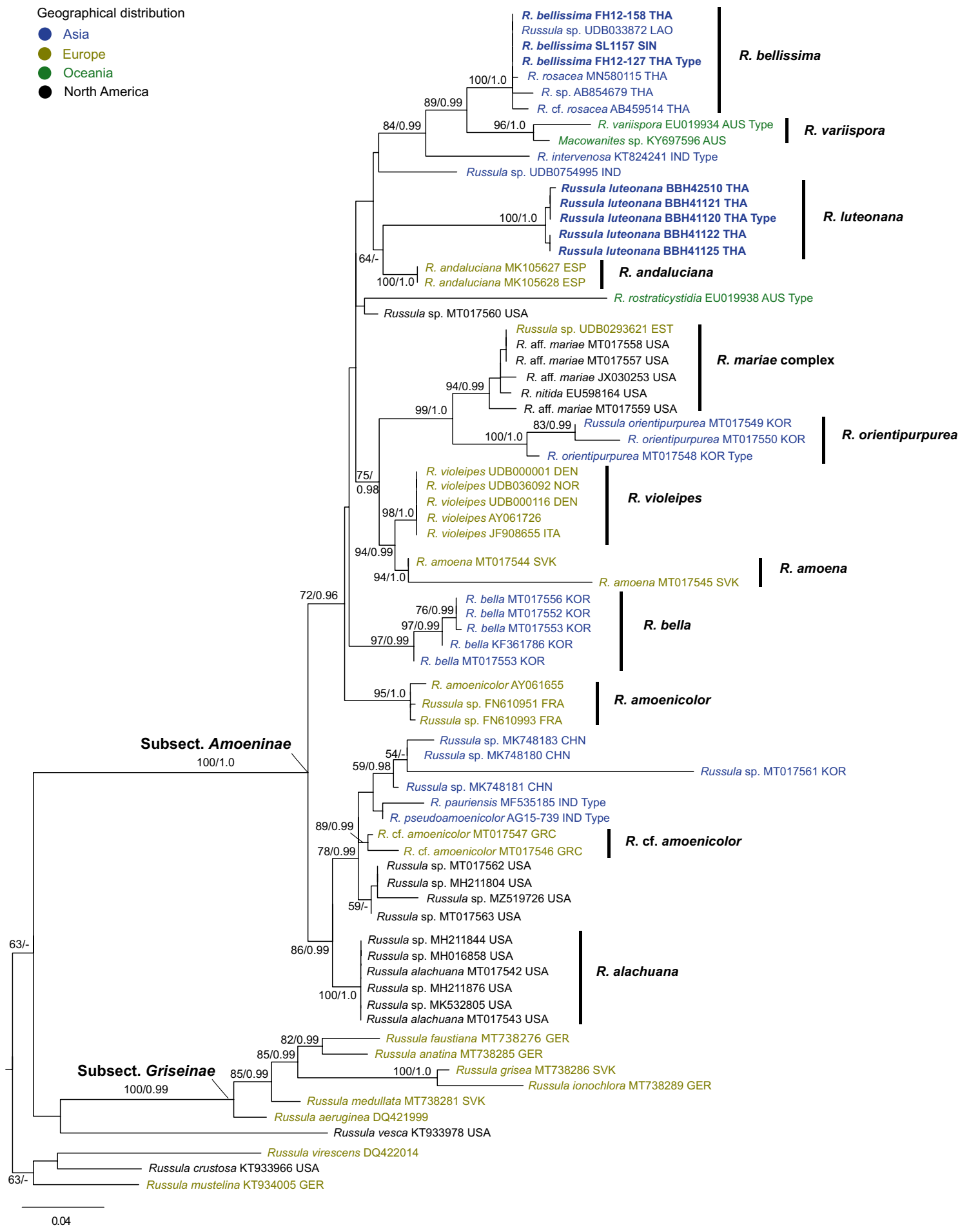

Figure 2. ML phylogenetic tree inferred from the ITS region of Russula subsection Amoeninae species and allied groups, using ML and BI methods. Samples in boldface are new species in this study. Bootstrap support values $(\mathrm{BS} \geq 50 \%)$ and posterior probabilities $(\mathrm{PP} \geq 0.90)$ are shown at the supported branches.

or lageniform, apically attenuated and acute, measuring (19-)27.5- $\underline{38.3}-49.0(-66.5) \times(3.3-) 4.5-\underline{5.8}-7.0(-9.0)$ $\mu \mathrm{m}$, rarely with a forked apex, mixed with dispersed, cylindrical or ellipsoid, distinctly shorter, obtuse terminal cells measuring (7.5-)11.5- $\underline{17.8}-29.5(-42.5) \times(3.0-) 4.0-\underline{4.5}-5.0 \mu \mathrm{m}$; subterminal cells measuring (4.5-)5.5- $\underline{8}$. $\underline{3}-11.5(-16.0) \times 4.5-5.3-6.0(-7.0) \mu \mathrm{m}$. Hyphal terminations near the pileus centre: similar in shape and also with a mixture of long acute and short obtuse terminal cells, acute ones measuring (12.0-)22.0-35.2-48.5(-79.0) $\times(2$ .5-)3.5-4.9-6.5(-8.0) $\mu \mathrm{m}$, obtuse ones more frequent, measuring (6.5-)8.5- $\underline{12.0}-15.5(-22.0) \times(3.5-) 4.0-\underline{4.9}-6$ $.0(-7.5) \mu \mathrm{m}$. Primordial hyphae or pileocystidia: absent. Cystidioid hyphae and oleipherous hyphae not observed.

Additional material studied THAILAND, Chiang Mai Province, Mae On District, about $3 \mathrm{~km}$ from Tharnthong lodges, $18^{\circ} 51^{\prime} 55^{\prime \prime} \mathrm{N} 99^{\circ} 17^{\prime} 23^{\prime \prime} \mathrm{E}$, alt. $725 \mathrm{~m}$, Dipterocarpaceae dominated forest with the presence of 

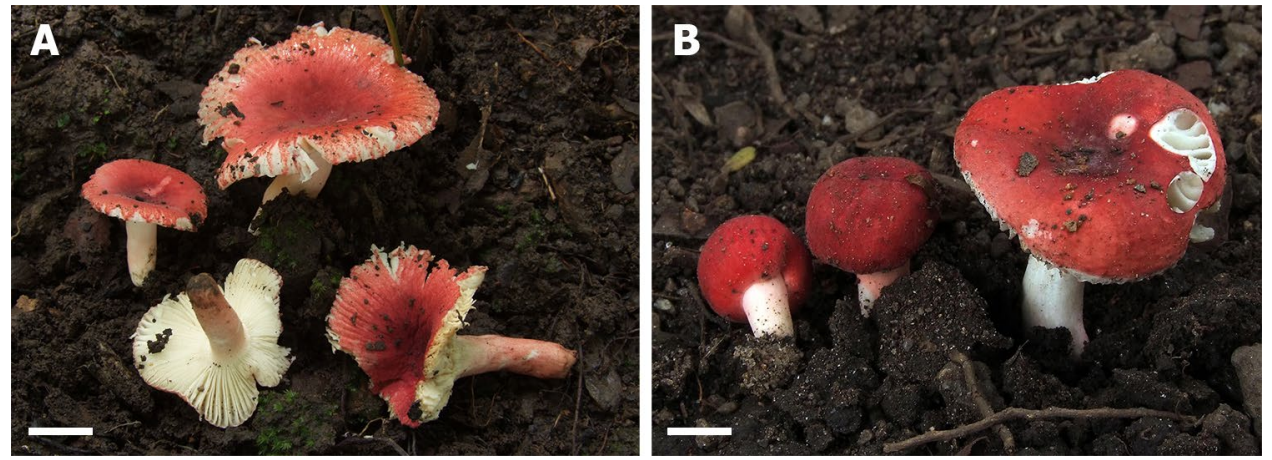

Figure 3. Basidiomata of Russula bellissima. (A) FH12-127 (Holotype). (B) FH12-158. Scale bar $=1 \mathrm{~cm}$. Photos by Felix Hampe.
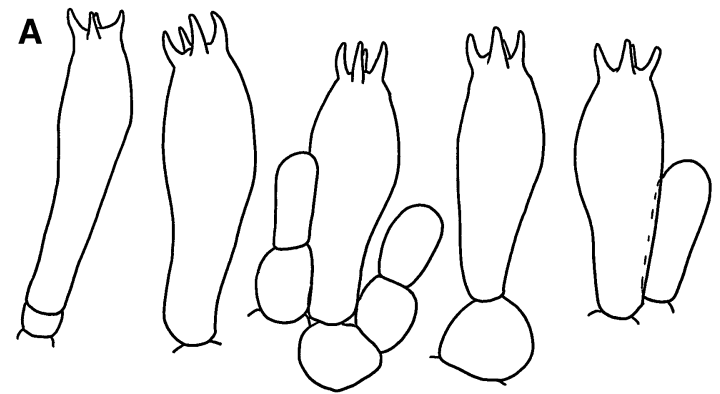

B

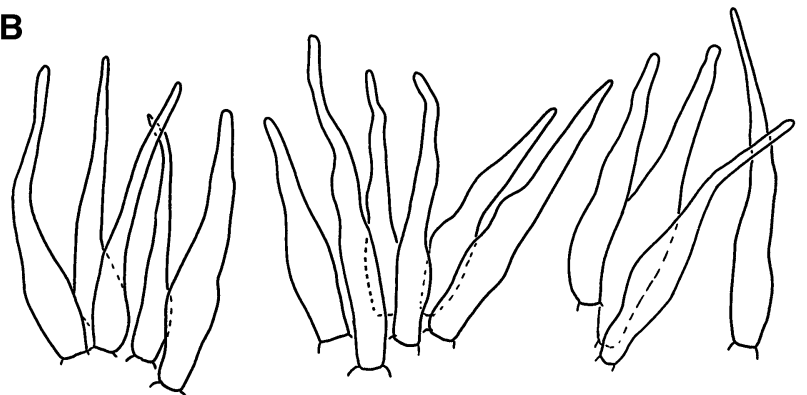

C

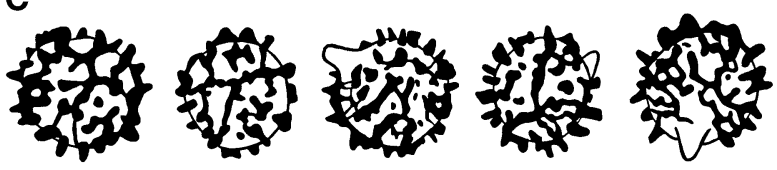

Figure 4. Hymenial elements of Russula bellissima (holotype, FH 12-127). (A) Basidia and basidiolae. (B) Marginal cells. (C) Spores as seen in Melzer's reagent. Scale bar $=10 \mu \mathrm{m}$, but only $5 \mu \mathrm{m}$ for spores.

some Castanopsis trees, in small groups on loamy soil, 17 July 2012, F. Hampe (GENT FH 12-158, duplicate: MFLU12-0648).

Note Russula bellissima is a small species with a bright red pileus and pink colour on the stipe. This colour is distinctive and resembles North American R. mariae, Indian R. intervenosa and Asian $R$. bella. It is very unlikely that the distribution of any European or North American species is overlapping with the Thai species. However, little is known about the distributional ranges and the ecological niches of other Asian Russula species. Therefore discussing the morphological distinguishing characters between Asian species and R. bellissima is more relevant. Russula bellissima is not closely related to $R$. bella and it differs from this species by larger spores with a more prominent spore ornamentation, absence of hymenial cystidia on lamellae sides, and subterminally short, ellipsoid cells in the suprapellis arranged in unbranched chains of up to four ${ }^{7}$. The Thai species resembles and is closely related to the Indian $R$. intervenosa, but it has a more prominent spore ornamentation, hymenial cystidia (on lamellae sides) are absent, and hyphal terminations in the pileipellis are wider ${ }^{22}$.

Russula luteonana M. Pobkwamsuk \& K. Wisitrassameewong sp. nov.. Mycobank: MB 840550. Holotype: THAILAND, Amnat Charoen province, Hua Taphan district, Junction near Watbochaneng, dry dipterocarp 


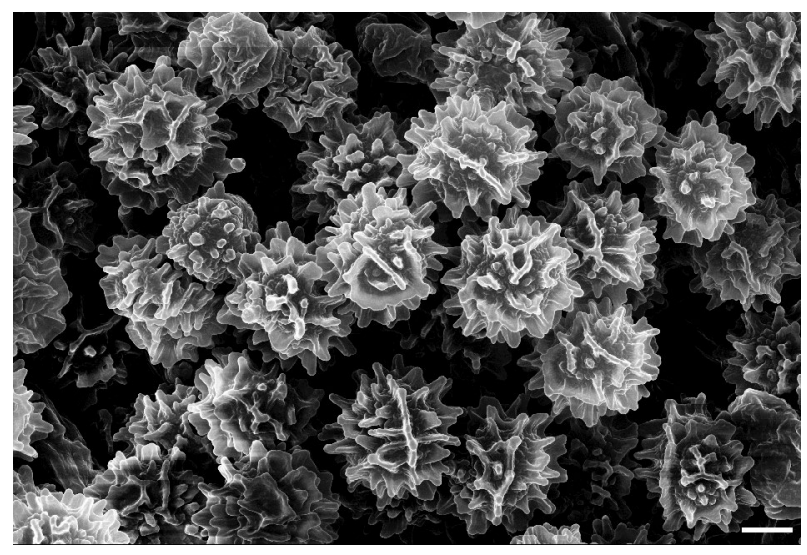

Figure 5. Scanning electron microscope photo of spore ornamentation. Russula bellissima (holotype, FH 12-127). Scale bar $=2 \mu \mathrm{m}$.
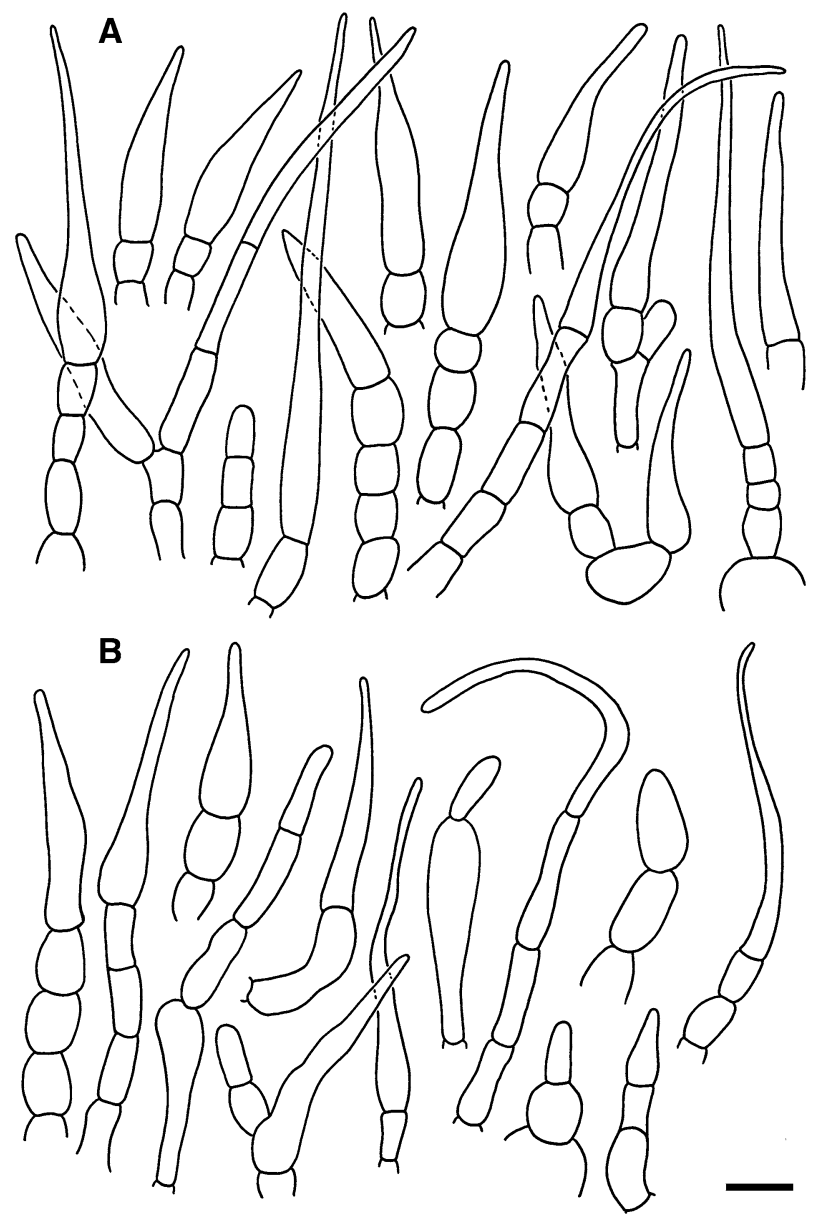

Figure 6. Elements of the pileipellis of Russula bellissima (holotype, FH 12-127). (A) Hyphal terminations near the pileus margin. (B) Hyphal terminations near the pileus centre. Scale bar $=10 \mu \mathrm{m}$.

forest, alt. $145 \mathrm{~m}, 15^{\circ} 41^{\prime} 28^{\prime \prime} \mathrm{N} \mathrm{104^{ \circ }} 31^{\prime} 41^{\prime \prime}$ E, 13 July 2016, Thitiya Boonpratuang, Rattaket Choeyklin, Prapapan Sawhasan, Maneerat Pobkwamsuk, Pattrachai Juthamas, Nattawut Wiriyathanawudhiwong, Patcharee Patangwesa (BBH41120).

Etymology 'Luteolus' = yellow colour, 'Nanus' = small. Refer to pileus color and size of the species. 

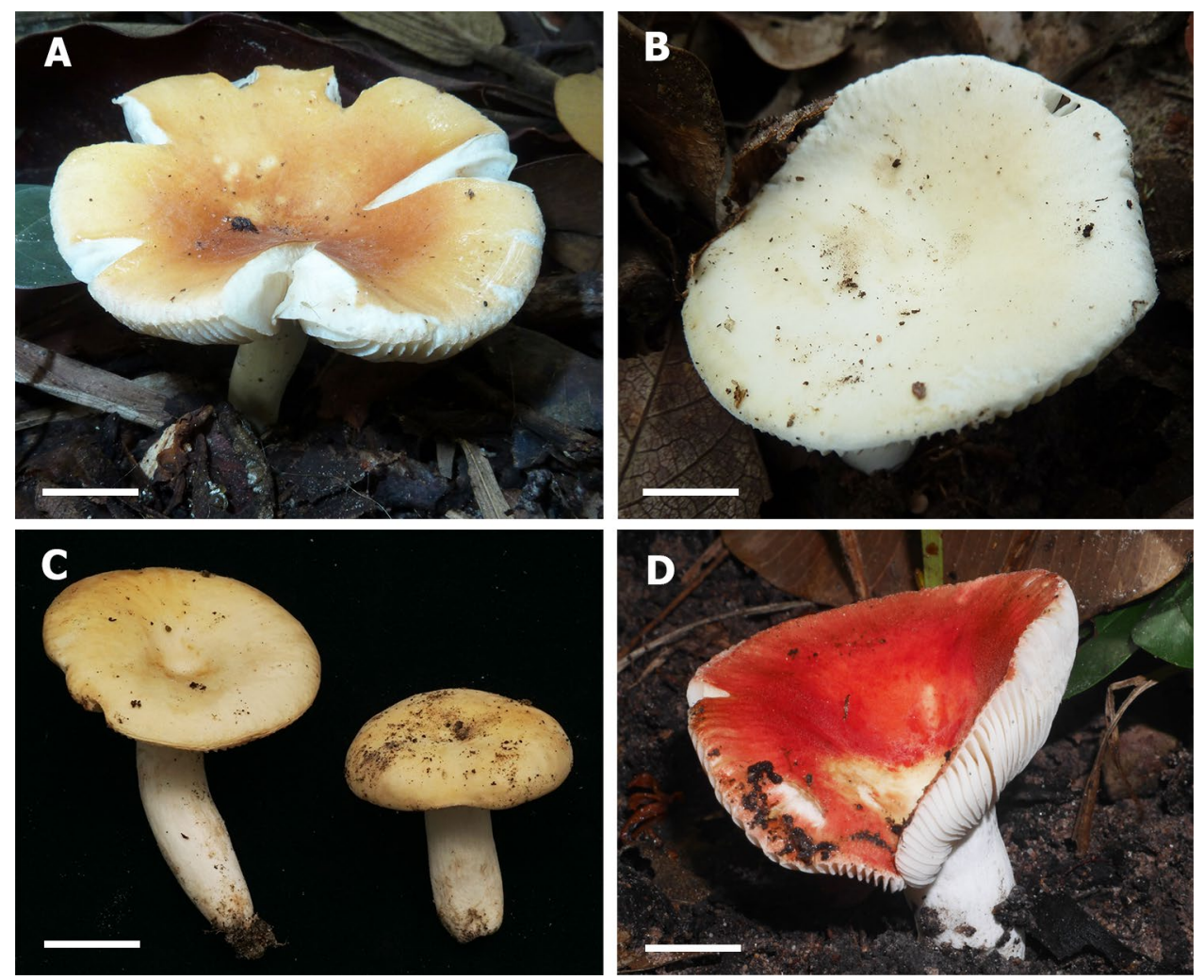

Figure 7. Basidiomata of Russula luteonana. (A) BBH41120 (Holotype). (B) BBH41121. (C) BBH41122. (D) BBH42510. Scale bar $=1 \mathrm{~cm}$. Photos by Thitiya Boonpratuang.

Diagnosis Pileus medium-sized, dry, usually yellow, spores with subreticulate amyloid ornamentation and inamyloid suprahilar spot, hymenial cystidia on lamellae sides large, lamellae edges with combination of subulate, clavate and pyriform marginal cells.

Pileus (Fig. 7) medium-sized, 28-53 mm diam., plano-convex with depressed centre, infundibuliform when mature; margin striated and radially cracking in dry condition; cuticle dry, peeling to almost $1 / 2$ of radius, smooth to minutely wrinkled, dull in dry condition, color very variable, some collections pale cream and with darker pale brownish-yellow centre, other yellow brownish and with darker orange-brown centre, sometimes also bright red-brown and with discolored centre, always with rusty-brown spots especially when near the centre. Lamellae: 3-5 mm deep, moderately distant, intervenose, forking near the stipe, white to cream, edges even, concolorous. Stipe: $26-40 \times 6-9 \mathrm{~mm}$, cylindrical or narrowed at the base, surface dry, longitudinally wrinkled, white, turning brown when bruised. Context: $2-4 \mathrm{~mm}$ in at the half pileus radius, soft, solid, becoming partially hollow when mature, white, unchanging when cut. Taste mild; odour rather strong, fishy. Spore print: not observed.

Spores (Figs. 8, 9) (7.4-)8.1- ․․ $-9(-10.1) \times(6.1-) 7.4-\underline{7.5}-7.9(-9.1) \mu \mathrm{m}$, subglobose to broadly ellipsoid, $\mathrm{Q}=(1.03-) 1.09-1.15-1.20(-1.30)$, ornamentation of moderately distant, obtuse, $(0.7-) 1.1-1.3-1.5(-1.9) \mu \mathrm{m}$ high spines, connected by abundant line connections $[(0-) 3-6(-8)$ in in a $3 \mu \mathrm{m}$ diam. circle], branched, forming an incomplete reticulum, crest irregularly wavy and occasionally fused $[(0-) 1-2(-5)$ fusions in the circle], isolated elements rare; suprahilar spot inamyloid. Basidia: $(29-) 34.5-39.1-44(-51.5) \times(10-) 12-13.2-14.5$ ( $-16.5) \mu \mathrm{m}$, clavate, 4 -spored, rarely 2 -spored, basidiola subcylindrical to subclavate, $(25.5-) 30-35.4-41(-47$ )$\times(9-) 11-\underline{12.2}-14(-16) \mu \mathrm{m}$. Hymenial cystidia on lamellae sides: usually protruding over other elements of hymenium, widely dispersed $\left(<350 / \mathrm{mm}^{2}\right),(65-) 78-92.1-106.5(-132) \times(10.5-) 14-17.4-21(-24) \mu \mathrm{m}$, fusiform to lageniform, apically obtuse to subacute, thin- or slightly thick-walled; contents homogenous, optically empty, negative in sulfovanillin. Lamellar edges: with dispersed basidia; Marginal cells: very abundant, mainly long and apically acute, resembling terminal cells in the pileipellis, $(28.5-) 41.5-\underline{55}-69(-93) \times(5.5-) 7.5-\underline{9.0}-10.5(-1$ 3) $\mu \mathrm{m}$, fusiform, rarely lanceolate or lageniform, often fasciculate; mixed with less frequent, distinctly shorter, broadly clavate or obpyriform elements $\mu \mathrm{m},(12.4-) 20.1-25.7-31.2(-44.0) \times(5.2-)-8.9-10.9-12.8(-14.8) \mu \mathrm{m}$. Pileipellis: (Fig. 10) orthochromatic in Cresyl blue, sharply delimited from the underlying context, 110-350 um deep; suprapellis a trichoderm of ascending or erect hyphal terminations, non-gelatinized, subpellis composed of dense, strongly gelatinized, horizontally oriented, narrow hyphae. Acid-resistant incrustations: absent. Hyphal terminations near the pileus margin: mainly unbranched, apically often flexuous, usually composed of distinctly longer terminal cells and a single subterminal short cells, thin-walled; terminal cells of two distinct types, either long and apically attenuated or short, subcylindrical and obtuse, constricted on septa, the long type (27.5-)44.5 $-\underline{60.7}-76.5(-100.5) \times(4.0-) 5-\underline{6.6}-8(-11.3) \mu \mathrm{m}$, subulate, narrowly fusiform or narrowly lageniform, apically acute ; the short type $(16.4-) 24.7-\underline{36.2}-47.8(-71.9) \times(3.7-) 4.7-\underline{5.7}-6.8(-7.7) \mu \mathrm{m}$, cylindrical, rarely narrowly clavate or somewhat apically narrowed, occasionally moniliform; subterminal cells shorter, mainly unbranched, 


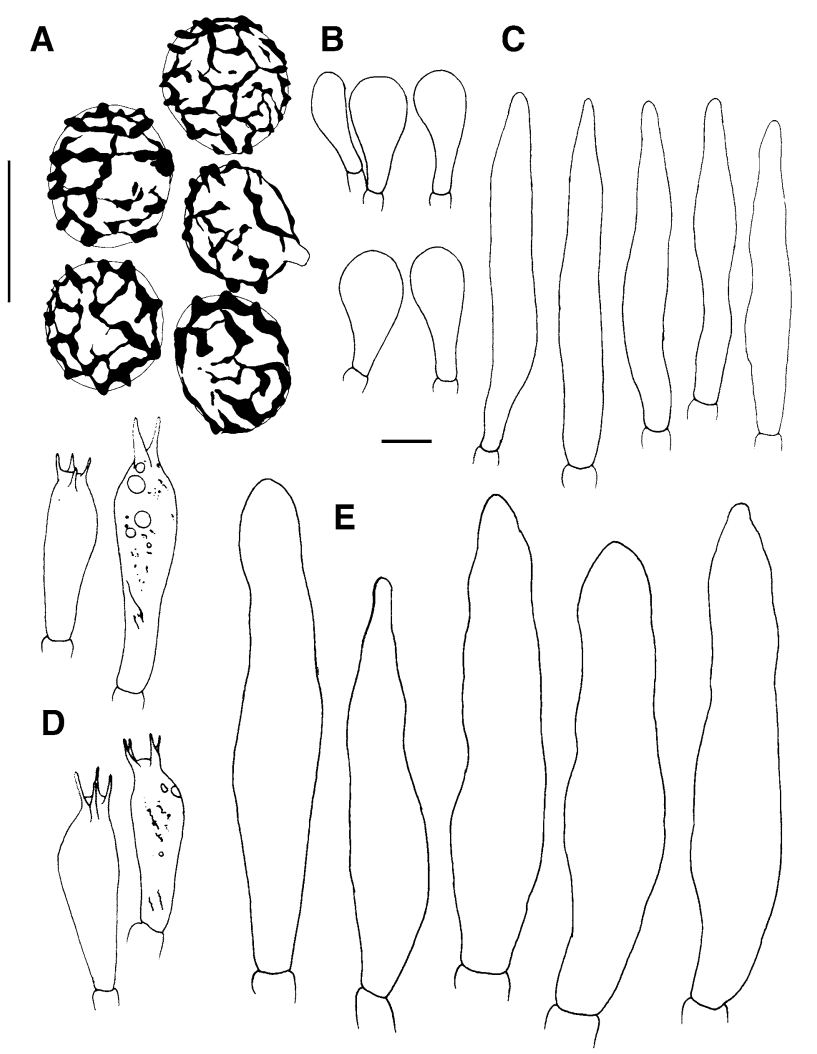

Figure 8. Hymenial elements of Russula luteonana (holotype, BBH41120). (A) Spores as seen in Melzer's reagent. (B) Clavate marginal cells. (C) Subulate marginal cells. (D) Basidia. (E) Hymenial cystidia on lamellae sides. Scale bar $=10 \mu \mathrm{m}$.

5-8 $\mu \mathrm{m}$ wide. Hyphal terminations near the pileus centre: similarly with terminal elements of two types, the longer type $(20-) 37.5-\underline{53}-69(-90) \times(3.5-) 5-\underline{6.1}-7.5(-9) \mu \mathrm{m}$, subulate and acute or subcylindrical and obtuse, the shorter type (12-)18.5-31.4-44.5(-65.5) $\times(3-) 4-5.0-6(-7) \mu \mathrm{m}$, subcylindrical, cylindrical, rarely narrowly clavate. Primordial hyphae or pileocystidia: absent. Cystidioid hyphae and oleipherous hyphae: in subpellis absent.

Additional material studied THAILAND, Amnat Charoen province, Hua Taphan district, Junction near Watbochaneng, dry dipterocarp forest, 13 July 2016, 3 collections from different mycelia at this site, Thitiya Boonpratuang, Rattaket Choeyklin, Prapapan Sawhasan, Maneerat Pobkwamsuk, Pattrachai Juthamas, Nattawut Wiriyathanawudhiwong, Patcharee Patangwesa, (BBH41121, BBH41122, BBH41125); ibid., 29 May 2017, Thitiya Boonpratuang, Rattaket Choeyklin, Maneerat Pobkwamsuk, Nattawut Wiriyathanawudhiwong, Tuksaporn Thummarukcharoen (BBH42510).

Note Russula luteonana is extremely variable but based on the pileus colour we can eliminate some species with purple or green tints. If we combine this with the white or nearly so stipe, it can only be confused with either $R$. bella (if it has redder colouration) or $R$. orientipurpurea. The unique character of $R$. luteonana is the large cystidia which range $14-21 \mu \mathrm{m}$ in width and are often also obtuse. While $R$. bella has many microscopic characters that distinguish it from this proposed species (e.g. smaller spores, narrower hymenial cystidia), $R$. orientipurpurea resembles, in many aspects, the Thai species (i.e. relatively large spores, obtuse and relatively wide hymenial cystidia on the lamellae sides, and usually only one unbranched short cell below the terminal cell of hyphae in pileipellis). Distinguishing features of these two species are the more prominent spore ornamentations and the often acute hymenial cystidia of R. luteonana ${ }^{7}$.

\section{Discussion}

Members of Russula subsect. Amoeninae were identified in the field based on the typical dryness of the pileus, the velvety-granulose aspect of pileus cuticle, and white lamellae. Later each collection was checked under the microscope for the absence of cystidia in the pileipellis. In the field, both new species are distinct from many other species, because of the pileus with red, yellow or brown tints and completely without purple or greenish colours. The stipes of both species are white or only partly flushed by pink, and never with purple or deep red on more than half of their surface. There is a high degree of infraspecific variability of pileus colours in Amoeninae and therefore field observations need sufficient sampling or further verifications under the microscope to identify them accurately to species ${ }^{7,23}$.

Microscopically, all Amoeninae representatives have a distinctive spore ornamentation composed of relatively prominent ridges and crests connected also by line connections to form a subreticulate to reticulate 


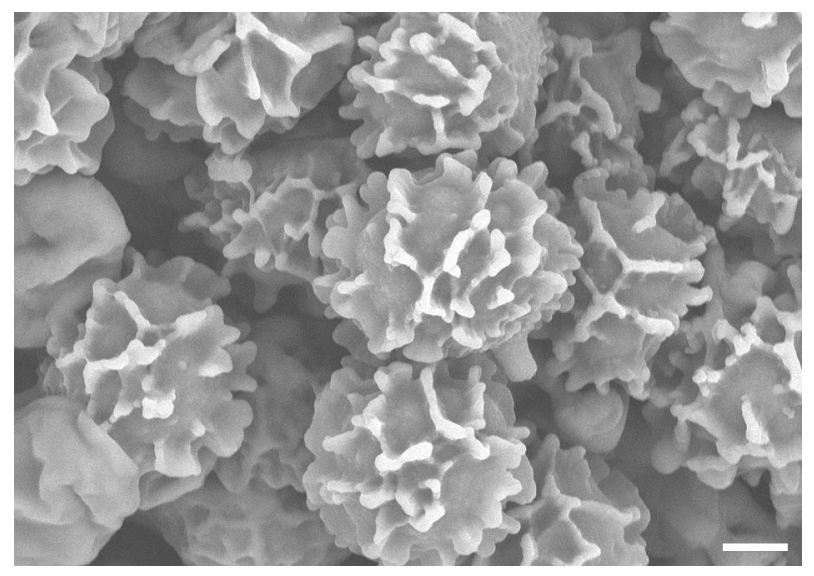

Figure 9. Spore ornamentation taken from scanning electron microscope. Russula luteonana (holotype, BBH41120). Scale bar $=2 \mu \mathrm{m}$.

A
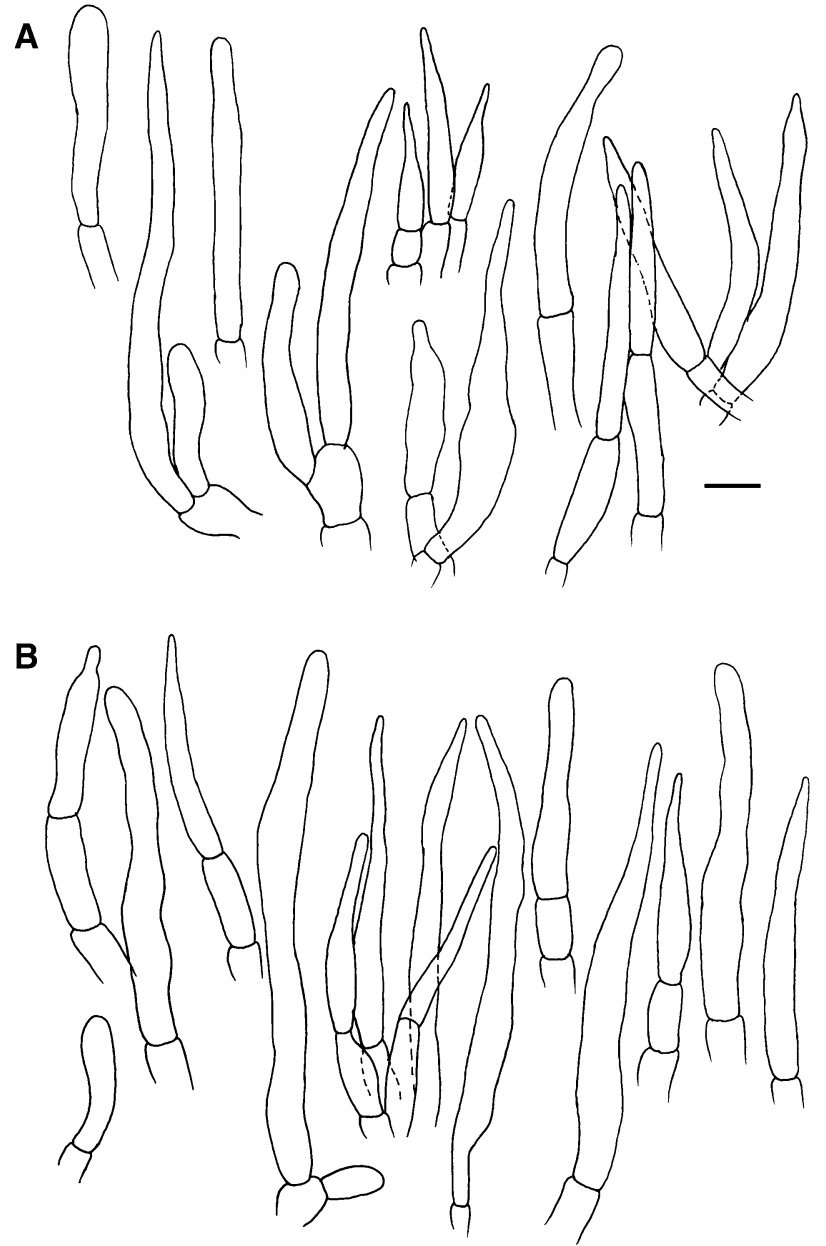

Figure 10. Elements of the pileipellis of Russula luteonana (holotype, BBH41120). (A) Hyphal terminations near the pileus margin. (B) Hyphal terminations near the pileus centre. Scale bar $=10 \mu \mathrm{m}$.

ornamentation. Both new species, $R$. bellissima and $R$. luteonana, typically have relatively large spores with prominent spore ornamentations that distinguishes them clearly from many of the Asian Amoeninae species (Table 1). Important features for species delimitation within Amoeninae are the hymenial cystidia and hyphal 
terminations in the pileipellis. While hymenial cystidia on lamellae sides are completely absent in R. bellissima, they are very large and often base-inflated (lageniform or subulate) in $R$. luteonana. Thus these microscopic structures distinguish both species from all known Asian Amoeninae. Hyphal terminations in the pileipellis are very different between the two newly described species and they prove importance of specific characters used already for European species, e.g. size of subterminal cells and their number ${ }^{7,23}$. Russula bellissima has relatively short terminal cells measuring up to $50 \mu \mathrm{m}$ and usually 2-3 short, subglobose subterminal cells that make it similar to $R$. intervenosa from India ${ }^{24}$. Russula luteonana has terminal cells usually longer than $50 \mu \mathrm{m}$ and zero to one cylindrical subterminal cells which make it similar to $R$. orientipurpurea ${ }^{7}$.

The first and only phylogenetically confirmed records of Amoeninae members in Thailand were published by Wisitrassameewong et $\mathrm{al}^{7}$, and they were represented by two samples with GenBank accession numbers AB459514 and AB854679. In our ITS analysis both these samples cluster within the R. bellisima clade together with three other samples from Thailand, Laos and Singapore. Our ITS tree covers nearly all previously published species of Amoeninae in Asia and all available sequence data of this group from public databases. The only Asian species without available DNA that are not included in our analyses are R. mukteswarica K. Das, S.L. Mill., J.R. Sharma \& R.P. Bhatt and R. punicea W.F. Chiu. Both of these species are morphologically very different from species described here. Russula mukteswarica has a purple and green coloured pileus and low spore ornamentation (only $0.75 \mu \mathrm{m}$ ), and the R. punicea has small spores (up to $7 \mu \mathrm{m}$ ) and small hymenial cystidia ${ }^{7}$. In conclusion, our study does not confirm any species of Amoeninae previously described or recorded from India, Korea, Japan or China occurring in Thailand. We were unable to locate any sequence record for $R$. luteonana in public sequence databases, but $R$. bellisima is represented by two additional sequences from Thailand and two more from Laos and Singapore. The Thailand sequences originated from a dry dipterocarp forest (GenBank accession number $\mathrm{AB} 854679$ ) and from an evergreen dipterocarp forest with annual precipitation of approximately $1030 \mathrm{mms}$ (GenBank accession number AB459514) ${ }^{27,28}$. The Laos record (UNITE accession number UDB033872) is from an urban area of Vientiane city on the northeastern Thai border and the Singapore record (GenBank accession number MZ519838) is also from Singapore Botanical Garden collected with Shorea leprosula. Because all collections of our new species are located in Mainland Southeast Asia, this result suggests that this area's endemic Russula diversity developed under specific climate, geomorphology and available ECM host range, such as already suggested for southwestern Himalayas ${ }^{29}$. In this respect it is worth to mention that sister to both our new species collected in dry dipterocarp forests are sequestrate species (Figs. 1,2) ${ }^{30}$ and both species can be members of two independent seasonal drought tolerant lineages within Amoeninae. Despite our effort, we did not collect any sequestrate species of Russula from dry dipterocarp forests, but during our field excursions, members of our expedition collected sequestrate Lactarius and Entoloma ${ }^{31,32}$.

The fungal flora of dipterocarp forests is still very poorly known, but there is a multitude of evidence that roots of Dipterocarpaceae trees are colonized by ectomycorrhizal fungi ${ }^{33}$. Based on sequencing of root tips, Dell et al. ${ }^{4}$ estimated that the fungal richness of dry dipterocarp forests in Thailand is comparable to other tropical rain forest sites, but the phylogenetic community structure has elements of both tropical and temperate ecosystems ${ }^{4}$. They confirmed insufficient knowledge of fungal species diversity of this habitat, only 9 of the 69 species matched with sequences from public databases at the $97 \%$ sequence similarity cut-off and only four of these taxa were identified to species based on the available reference sequences and identifications. In terms of species richness, Russulaceae lineage was the richest and a Russula cf. pectinata was the most frequent molecular operational taxonomic unit retrieved from all dataset. Phosri et al. ${ }^{3}$ reported that the diversity of ECM fungi in dipterocarp forests in Northern Thailand is the second most abundant after Fagaceae forest and the Russula-Lactarius lineage was among the dominant fungal groups. In lowland dry dipterocarp forest of Malaysia, Russula is reported as one the most abundant genera found from bulk soil and root tip samples ${ }^{34}$. Recent extensive mycological surveys in Southeast Asia resulted in the discoveries of several new ECM species specific to Dipterocarpaceae dominated forests, for example species of Lactarius subg. Plinthogalus (Burl.) Hesler \& A.H. Sm. From Malaysia ${ }^{35,36}$, Amanita Pers. and Lactifluus (Pers.) Roussel from northern Thailand ${ }^{37-40}$, Erythrophylloporus Ming Zhang \& T.H. Li from Northern Thailand ${ }^{41}$ and Sutorius Halling, Nuhn \& Fechner from northern and northeastern Thailand ${ }^{42}$. New Amoeninae species are not the first Russula members described from dry dipterocarp forests, also R. aurantiopectinata was collected and is reported with Dipterocarpus tuberculatus from this type of habitat ${ }^{12}$. However, our study is the first discussing possibly unique ectomycorrhizal communities and species adapted to this kind of ecological and climatic conditions.

To understand distributional ranges of Russula species collected in dry dipterocarp forests, we need to understand their niche limits in term of habitat specificity, ecological adaptations to certain climate and soil conditions, and their life strategy in general. Based on sequencing of Dipterocarpaceae root samples, Sato et al. ${ }^{43}$ suggested that specific lineages of closely related dipterocarp taxa are associated with some specific ECM forming Basidiomycota OTUs and have uniquely characteristic community structure. However, seedling experiments of Dipterocarpaceae species with contrasting soil specializations proved that there is little host specificity and soil environment was the primary determinant of ectomycorrhizal diversity ${ }^{44}$. This result is in contrast with the study of Essene et al. $^{34}$, reporting that majority of the taxa detected in root tip samples had not only restricted preference of soil type (either sand or clay soil), but also were associated with only one species of Shorea. Two different Shorea tree species on the same soil type were colonized by different ECM fungal communities. These results suggested that these biotic and abiotic factors might have played a role in structuring ECM fungal communities in Dipterocarpaceae forests.

In Thailand, wild edible mushrooms are one of the three main non-timber forest products collected during the rainy season ${ }^{45}$. Mushroom foraging is considered to be a recreational activity, seasonal food source, or an option for additional household income. Several species of Russula are considered choice for consumption in rural regions, particularly in northern and northeastern Thailand and they are a commonly eaten mushrooms in the region due to their high yields in Thai forests. Various morphological types of Russula are frequently 


\begin{tabular}{|c|c|c|c|c|c|c|c|c|c|}
\hline & R. bella (1) & $\begin{array}{l}R . \\
\text { orientipurpurea } \\
(1)\end{array}$ & $R$. sp. (1) & $\begin{array}{l}\text { R. intervenosa } \\
\text { (2) }\end{array}$ & \begin{tabular}{|l}
$R$. \\
pseudoamoenicolor \\
$(3)$
\end{tabular} & R. pauriensis (4) & $\begin{array}{l}\text { R. mukteswarica } \\
\text { (5) }\end{array}$ & R. bellissima (6) & R. luteonana (6) \\
\hline Pileus size (mm) & $20-50$ & $52-60$ & 60 & 26-49 & $50-100$ & $53-63$ & 65-130 & $10-50$ & $28-53$ \\
\hline \multicolumn{10}{|l|}{ Pileus colour } \\
\hline Bright red & 1 & & & 1 & 1 & & & 1 & 1 \\
\hline Pink & 1 & & & 1 & & & & & \\
\hline Grey & & 1 & 1 & & & 1 & & & \\
\hline Brown & & & & & & & & & 1 \\
\hline Purple & & 1 & & & 1 & & 1 & & \\
\hline Violet & & & 1 & & 1 & 1 & 1 & & \\
\hline Green & & & & & & 1 & 1 & & \\
\hline Bright yellow & & & & 1 & & & 1 & & 1 \\
\hline $\begin{array}{l}\text { Cream or pale } \\
\text { yellow }\end{array}$ & & 1 & & & & & & & 1 \\
\hline \multicolumn{10}{|l|}{ Stipe colour } \\
\hline Almost white & 1 & 1 & 1 & & & & & & 1 \\
\hline Partly pink & & & & 1 & 1 & & 1 & 1 & \\
\hline Partly purple & & & & 1 & 1 & 1 & 1 & & \\
\hline Partly violet & & & & & & 1 & & & \\
\hline \multicolumn{10}{|l|}{ Spore size } \\
\hline Length $(\mu \mathrm{m})$ & $6.5-7.7$ & \begin{tabular}{|l|}
$6.9-7.8$ \\
\end{tabular} & $6.5-7$ & $7-8$ & $6-9.5$ & $6-8$ & $7.6-9.3$ & $7.3-8.3$ & $8.1-9.0$ \\
\hline Width $(\mu \mathrm{m})$ & $5.3-6.0$ & $6-6.9$ & $5.6-6.2$ & $6.5-7$ & $5-8$ & $5.5-7$ & $7.3-8.2$ & $6.8-7.6$ & $7.4-7.9$ \\
\hline \multicolumn{10}{|c|}{ Spore ornamentation } \\
\hline Height $(\mu \mathrm{m})$ & $0.4-1.0$ & $0.6-1$ & $0.7-1.2$ & $0.6-0.9$ & Up to 2 & Up to 2 & 0.75 & $1.2-1.6$ & $1.1-1.2$ \\
\hline Subreticulate & 1 & 1 & 1 & 1 & 1 & 1 & 1 & 1 & 1 \\
\hline Reticulate & & 1 & & & & & & & \\
\hline \multicolumn{10}{|l|}{ Hymenial cystidia } \\
\hline Length $(\mu \mathrm{m})$ & $52-75$ & 74.5-101 & $12.5-16.5$ & $29-34$ & 90-117 & $55-135$ & $80-110$ & & 78-106.5 \\
\hline Width $(\mu \mathrm{m})$ & $7.5-10.5$ & $10.5-15$ & & $10-12.5$ & $10-21$ & $12-22$ & $11-17$ & & $14-21$ \\
\hline $\begin{array}{l}\text { Cylindrical or } \\
\text { clavate }\end{array}$ & 1 & & & & & & & & \\
\hline $\begin{array}{l}\text { Subulate or } \\
\text { lageniform }\end{array}$ & & & 1 & & & & & & 1 \\
\hline Fusiform & & 1 & 1 & 1 & 1 & 1 & 1 & & 1 \\
\hline Obtuse & 1 & 1 & & & 1 & 1 & & & 1 \\
\hline Acute & & & 1 & 1 & & 1 & & & \\
\hline \multicolumn{10}{|l|}{ Marginal cell } \\
\hline Length $(\mu \mathrm{m})$ & $38.5-63$ & $48-88$ & $42.5-56.5$ & $32-39$ & $30-85$ & $36-68$ & $70-100$ & $38.5-54.5$ & $41.5-69$ \\
\hline Width $(\mu \mathrm{m})$ & $5.5-7.5$ & $5.5-10.5$ & $5.5-7$ & $5.5-7$ & $7-10$ & $8-15$ & $11-17$ & $5.5-7.5$ & \begin{tabular}{|l|}
$7.5-10.5$ \\
\end{tabular} \\
\hline $\begin{array}{l}\text { Different from } \\
\text { sides }\end{array}$ & 1 & 1 & 1 & 1 & & & & 1 & 1 \\
\hline \multicolumn{10}{|l|}{ TC margin } \\
\hline Length $(\mu \mathrm{m})$ & $47-76$ & $55.5-89$ & $60-85$ & $39-47$ & $11-65$ & $9-64$ & & $27.5-49$ & $24.7-76.5$ \\
\hline Width $(\mu \mathrm{m})$ & $5-7$ & $5-7$ & $4.5-6$ & $2.5-4.5$ & $4-10$ & $4-10$ & $5-11$ & $4.5-7$ & $4.7-8$ \\
\hline \multicolumn{10}{|l|}{ Subterminal cell } \\
\hline Number & $1-2$ & $0-2$ & $1-2$ & & & $2-4$ & $2-4$ & $1-4$ & $0-1$ \\
\hline Width $(\mu \mathrm{m})$ & & & & & Up to 14 & Up to 12 & & $4.5-6$ & $4-8$ \\
\hline \multicolumn{10}{|l|}{ TC centre } \\
\hline Width $(\mu \mathrm{m})$ & $4.5-7.5$ & $4.5-7.5$ & $3-4$ & & & & & $3.5-6.5$ & $4-7.5$ \\
\hline
\end{tabular}

Table 1. Comparison of selected morphological characters of known Amoeninae species from Asia and species described in this study. Sources of descriptions: (1) Wisitrassameewong et al. ${ }^{7}$, (2) Crous et al. ${ }^{22}$, (3) Hyde et al. ${ }^{25}$, (4) Das et al. ${ }^{24}$, (5) Das et al. ${ }^{26}$, (6) this study.

sold in local markets e.g. reddish cap (called R. cf. emetica or $R$. cf. rosacea), whitish cracked cap (called R. cf. alboareolata), cream to brownish cap (called $R$. cf. heterophylla) or greenish cap (called R. virescens) ${ }^{8,46}$. Due to the pileus colour, $R$. bellissima and $R$. luteonana probably can match $R$. cf. rosacea and $R$. cf. heterophylla morphotypes, respectively. Accordingly, two of $R$. bellissima ITS sequences retrieved from GenBank were labeled 
as $R$. cf. rosacea. Globally, two Amoeninae members, $R$. mariae and $R$. violeipes are known as edible fungi used for consumption as well as members of other related lineages like subsections Virescentinae and Heterophyllae (Fr.) Jul. Schäff. that are well known edible fungi ${ }^{47}$. Therefore, it is likely that the two species described in this study are edible. However, the correct identification of well documented edible species is important because a number of Russula species are reported as poisonous ${ }^{48,49}$ or can cause gastrointestinal irritations, and the latter ones include Russula collections identified as $R$. cf. rosace $a^{50}$.

\section{Materials and methods}

Studied collections and morphological study. Our collections originated from dry dipterocarp forests in two distant areas of Thailand collected in 2012-2017. Two collections (FH12-127 and FH12-158) were collected at two locations in northern Thailand at altitudes of 500-700 m. These samples were deposited in Mae Fah Luang University (MFLU) and Ghent University (GENT). Five collections (BBH41120, BBH41121, BBH41122, BBH41125, BBH42510) were collected in northeastern Thailand, at altitudes of 100-200 m. These five collections were deposited in BIOTEC Bangkok Herbarium of National Biobank of Thailand (BBH). Macroscopic characters were all recorded based on fresh material. For the terminology of macroscopic features, we followed Vellinga et al. ${ }^{51}$. The colour codes follow Kornerup and Wanscher ${ }^{52}$.

To describe all microscopic features, we used the description template and terminology of Adamčík et al. ${ }^{6}$. Microscopic characters were studied on dried material mainly in Congo Red ${ }^{53}$, except for spore morphology, which was observed in Melzer reagent. Chemical tests were applied with Cresyl Blue ${ }^{54}$, sulfovanillin ${ }^{55}$, and carbolfuchsin ${ }^{56}$ to observe colour changes, incrustations, and cystidia contents. Line drawings and measurements of all microscopic characters were done using Nikon Eclipse Ni (Nikon Instrument Inc., Japan), with the aid of the software NIS-element BR 5.02.03 at a projection scale of $2000 \times$. Scanning electron microscopy (SEM) images were done using Zeiss Auriga crossbeam microscope at a $6330 \times$ magnification and FESEM Hitachi SU5000 at a $5000 \times$ magnification. Ranges of measurements were estimated as average plus/minus two times of standard deviation; in parenthesis are minimum and maximum values. Q value corresponds to length/width ratio of spores. The central value in italics represents an average. The measurements of all microscopic characters of a species were observed for three collections if available with 30 measurements per collection.

DNA extraction, PCR amplification and sequencing. Genomic DNA was extracted from dried materials using E.Z.N.A. Forensic DNA kit (Omega Bio-Tek). The amplification of the internal transcribed spacer region (ITS) of the nuclear ribosomal DNA was done using primers ITS1- $\mathrm{F}^{57}$ and ITS4 ${ }^{58}$. The primers RPB2-6F and $\mathrm{fRPB} 2-7 \mathrm{cr}^{59}$ and the primers MS1 and $\mathrm{MS}^{28}$ were used to amplify the second largest subunit of RNA polymerase II ( $r p b 2)$ and mitochondrial small subunit ribosomal DNA region (mtSSU), respectively. DNA sequencing of the successful PCR products using the same primers was performed by an ABI 3500 Genetic analyzer (Thermo Fisher Scientific) at the National Biobank of Thailand. Obtained sequences were checked and edited using FinchTV 1.4 (Geospiza, Inc.) and then assembled in MEGA X ${ }^{60}$.

Alignment and phylogenetic analyses. Phylogenetic analysis was based on three DNA regions: ITS nrDNA, mtSSU and rpb2. The DNA sequences of Amoeninae members used for the multi-loci analysis were downloaded from GenBank (https://www.ncbi.nlm.nih.gov/genbank/) based on the previous study of Wisitrassameewong et al. ${ }^{7}$ (Supplementary Table 1). Three other members of $R$. subg. Heterophyllidiae, R. aff. crustosa, $R$. grisea, and R. vesca, were chosen as an outgroup for this multi-locus analysis. For better estimation of overall diversity of Amoeninae, we downloaded available ITS Amoeninae sequences with special emphasis to Asian taxa. Our selection of ITS sequences covers species recognized by Wisitrassameewong et al. ${ }^{7}$ and additionally also all Asian members with at least 90\% BLAST similarity to any described Amoeninae member. We also searched the UNITE database (https://unite.ut.ee/) for Asian samples matching Amoeninae with a 3\% identity threshold. Based on previous phylogenetic studies, members of the other subsections of $R$. subg. Heterophyllidia were included in the ITS dataset and members of $R$. subsect. Virescentinae Singer was selected as the outgroup. All datasets were aligned using MAFFT $^{61}$. We inferred phylogenies for each single-gene dataset using Maximum Likelihood (ML). ML analyses were performed using RAxML 8.2.12 ${ }^{62}$. The parameters for RAxML analyses were the GTRGAMMA model and the rapid bootstrapping algorithm for 1,000 replicates. We compared the tree topology between different single-gene trees and examined for conflict at nodes with bootstrap support value (BS) above $70 \%$ and posterior probability (PP) higher than 0.90 . A conflict can be considered as significant if two different relationships for the same set of taxa were observed among different single-gene phylograms. A concatenated dataset of ITS $+r p b 2+\mathrm{mtSSU}$ was constructed using BioEdit 7.2.563. jModelTest 2.1.6 was used to estimate the best-fit model of substitution for each partition ${ }^{64}$. The models based on Bayesian information criterion (BIC) were selected as follows: $\mathrm{K} 80+\mathrm{G}$ for $r p b 2$ pos1, rpb2pos2 and rpb2pos3, TIM1 + G for mtSSU, $\mathrm{K} 80+\mathrm{G}$ for ITS1, TPM1 for $5.8 \mathrm{~s}$ rDNA and TrNef $+\mathrm{G}$ for ITS2 regions. Bayesian Inference (BI) analysis was executed using MrBayes 3.2.7 $\mathrm{a}^{65}$. The analysis was executed for four independent runs with four chains each that was run for 10 million generations and sampled every 100th tree until the standard deviation of split frequency was less than 0.01 . Before finalizing a consensus tree, the convergence and ESS values were checked using Tracer $1.6^{66}$. The burn-in of 10,000 for each run was used. All phylogenetic analyses were done using the CIPRES Science Gateway ${ }^{67}$. 
Received: 3 September 2021; Accepted: 2 February 2022

Published online: 18 February 2022

\section{References}

1. Buyck, B., Zoller, S. \& Hofstetter, V. Walking the thin line... ten years later: The dilemma of above- versus below-ground features to support phylogenies in the Russulaceae. Fungal Divers 89, 267-292. https://doi.org/10.1007/s13225-018-0397-5 (2018).

2. Buyck, B. et al. One step closer to unravelling the origin of Russula: Subgenus Glutinosae subg. nov. Mycosphere 11, 285-304. https://doi.org/10.5943/mycosphere/11/1/6 (2020).

3. Phosri, C. et al. Diversity and community composition of ectomycorrhizal fungi in a dry deciduous dipterocarp forest in Thailand. Biodivers. Conserv. 21, 2287-2298. https://doi.org/10.1007/s10531-012-0250-1 (2012).

4. Dell, B., Sanmee, R., Lumyong, P. \& Lumyong, S. Ectomycorrhizal Fungi in Dry and Wet Dipterocarp Forests in Northern ThailandDiversity and Use as Food (2011). http://park.dnp.go.th/dnp/research/1024020511_123052.pdf.

5. Chandrasrikul, A. et al. Checklist of Mushrooms (Basidiomycetes) in Thailand. (Office of Natural Resources and Environmental Policy and Planning, 2011). ISBN 978-974-286-858-1.

6. Adamčík, S. et al. The quest for a globally comprehensible Russula language. Fungal Divers 99, 369-449. https://doi.org/10.1007/ s13225-019-00437-2 (2019).

7. Wisitrassameewong, K. et al. Taxonomic revision of Russula subsection Amoeninae from South Korea. MycoKeys 75, 1-29. https:// doi.org/10.3897/mycokeys.75.53673 (2020).

8. Manassila, M., Sooksa-Nguan, T., Boonkerd, N., Rodtong, S. \& Teaumroon, N. Phylogenetic diversity of wild edible Russula from Northeastern Thailand on the basis of the internal transcribed spacer sequence. ScienceAsia 31, 323-328. https://doi.org/10.2306/ scienceasia1513-1874.2005.31.323 (2005).

9. Yuwa-Amornpitak, T., Vichitsoonthonkul, T., Tantichareon, M., Cheevadhanarak, S. \& Ratchadawong, S. Diversity of ectomycorrhizal fungi on Dipterocarpaceae in Thailand. J. Biol. Sci. 6, 1059-1064. https://doi.org/10.3923/jbs.2006.1059.1064 (2006).

10. Kaewgrajang, T., Kaewjunsri, S., Jannual, N. \& Nipitwattanaphon, M. Morphological and molecular identification of some Lactarius and Russula species. Genom. Genet. 13, 44-58. https://doi.org/10.14456/gag.2020.6 (2020).

11. Yomyart, S., Piapukiew, J., Watling, R., Whalley, A. J. S. \& Sihanonth, P. Russula siamensis: A new species of annulate Russula from Thailand. Mycotaxon 95, 247-254 (2006).

12. Hampe, F. \& Manz, C. Two new Russula species from Thailand and the new subsection Magicae. Z. Mykol. 81, 17-30 (2021).

13. Schulte, A. \& Schöne, D. Dipterocarp Forest Ecosystems: Towards Sustainable Management (World Scientific Publishing, 1996). https://doi.org/10.1142/3160.

14. Cvetković, T., Hinsinger, D. D. \& Strijk, J. S. Exploring evolution and diversity of Chinese Dipterocarpaceae using next-generation sequencing. Sci. Rep. 9, 11639:1-11639:12. https://doi.org/10.1038/s41598-019-48240-y (2019).

15. Appanah, S. \& Turnbull, J. M. A review of Dipterocarps: Taxonomy, Ecology and Silviculture (Center for International Forestry Research, 1998). ISBN: 979-8764-20-X.

16. Smitinand, T. The distribution of the Dipterocarpaceae in Thailand. In XIth Pacific Science Congress, Tokyo, Japan, 1st September 1966 67-76.

17. Pooma, R. Further notes on Thai Dipterocarpaceae. Thai Forest Bull. 30, 7-27 (2002).

18. Wohlfart, C., Wegmann, M. \& Leimgruber, P. Mapping threatened dry deciduous dipterocarp forest in South-east Asia for conservation management. Trop. Conserv. Sci. 7, 597-613. https://doi.org/10.1177/194008291400700402 (2014).

19. Gardner, S., Sidisunthorn, P. \& Anusarnsunthorn, V. A Field Guide to Forest Trees of Northern Thailand (Kobfai Publishing Project, 2000). ISBN: 9789748367293

20. Sahunalu, P. Stand structure and species composition in the long-term dynamic plots of Sakaerat deciduous Dipterocarp Forest, Northeastern Thailand. J. For. Manag. 3, 1-20 (2009).

21. Buyck, B. Etude microscopique des specimens-types de Russules tropicales de la sous-section Diversicolores. Mycotaxon 33, 57-70 (1988).

22. Crous, P. W. et al. Fungal planet description sheets 400-468: Russula intervenosa S. Paloi, A.K. Dutta \& K. Acharya sp. nov. Persoonia 36, 316-458. https://doi.org/10.3767/003158516X692185 (2016).

23. Sarnari, M. Monographia Illustrata del Genere Russula in Europa (Associazioni Micologica Bresadola, 1998).

24. Das, K. et al. Fungal biodiversity profile 31-40. Cryptogam. Mycol. 38, 353-406. https://doi.org/10.7872/crym/v38.iss3.2017.353 (2017).

25. Hyde, K. D. et al. Fungal diversity notes 367-490: Taxonomic and phylogenetic contribution to fungal taxa. Fungal Divers. 80, 1-270. https://doi.org/10.1007/s13225-016-0373-x (2016).

26. Das, K., Miller, S. L., Sharma, J. R., Sharma, P. \& Bhatt, R. P. Russula in Himalaya 1: A new species of subgenus Amoenula. Mycotaxon 94, 85-88 (2005)

27. Kaewgrajang, T., Sangwanit, U., Kodama, M. \& Yamato, M. Ectomycorrhizal fungal communities of Dipterocarpus alatus seedlings introduced by soil inocula from a natural forest and a plantation. J. For. Res. 19, 260-267. https://doi.org/10.1007/s10310-0130408-z (2014).

28. Ruankaew Disyatat, N., Yomyart, S., Sihanonth, P. \& Piapukiew, J. Community structure and dynamics of ectomycorrhizal fungi in a dipterocarp forest fragment and plantation in Thailand. Plant Ecol. Divers. 9, 577-588. https://doi.org/10.1080/17550874.2016. 1264018 (2016).

29. Kiran, M., Caboň, M., Senko, D., Khalid, A. N. \& Adamčík, S. Description of the fifth new species of Russula subsect. Maculatinae from Pakistan indicates local diversity hotspots of ectomycorrhizal fungi in Southwestern Himalayas. Life 11, 662:1-662:14. https:// doi.org/10.3390/life11070662 (2021).

30. Vidal, J. M. et al. A phylogenetic and taxonomic revision of sequestrate Russulaceae in Mediterranean and temperate Europe. Persoonia 42, 127-185. https://doi.org/10.3767/persoonia.2019.42.06 (2019).

31. Verbeken, A. et al. A new angiocarpous Lactarius species from Thailand. Phytotaxa 181, 163-170. https://doi.org/10.11646/phyto taxa.181.3.4 (2014)

32. Elliott, T. F., Nelsen, D. J., Karunarathna, S. C. \& Stephenson, S. L. Entoloma sequestratum, a new species from northern Thailand, and a worldwide key to sequestrate taxa of Entoloma (Entolomataceae). Fungal Syst. Evol. 6, 253-263. https://doi.org/10.3114/ fuse.2020.06.12(2020).

33. Brearley, F. Q. Ectomycorrhizal associations of the Dipterocarpaceae. Biotropica 44, 637-648. https://doi.org/10.1111/j.1744-7429. 2012.00862.x (2012).

34. Essene, A. L., Shek, K. L., Lewis, J. D., Peay, K. G. \& McGuire, K. L. Soil type has a stronger role than dipterocarp host species in shaping the ectomycorrhizal fungal community in a Bornean lowland tropical rain forest. Front. Plant Sci. 8, 1828:1-1828:10. https://doi.org/10.3389/fpls.2017.01828 (2017).

35. Stubbe, D., Verbeken, A. \& Watling, R. Blue-staining species of Lactarius subgenus Plinthogali in Malaysia. Belg. J. Bot. 140, 197-212. https://doi.org/10.2307/20794639 (2007)

36. Stubbe, D., Nuytinck, J. \& Verbeken, A. Lactarius subgenus Plinthogalus of Malaysia. Fungal Divers. 32, 125-156 (2008).

37. Sanmee, R., Tulloss, R. E., Lumyong, P., Dell, B. \& Lumyong, S. Studies on Amanita (Basidiomycetes: Amanitaceae) in Northern Thailand. Fungal Divers. 32, 97-123 (2008). 
38. Van de Putte, K., Nuytinck, J., Stubbe, D., Le, H. T. \& Verbeken, A. Lactarius volemus sensu lato (Russulales) from northern Thailand: Morphological and phylogenetic species concepts explored. Fungal Divers. 45, 99-130. https://doi.org/10.1007/s13225010-0070-0 (2010).

39. De Crop, E. et al. Novel diversity in Lactifluus section Gerardii from Asia: Five new species with pleurotoid or small agaricoid basidiocarps. Mycologia 110, 962-984. https://doi.org/10.1080/00275514.2018.1508979 (2018).

40. Dierickx, G. et al. Updated taxonomy of Lactifluus section Luteoli: L. russulisporus from Australia and L. caliendrifer from Thailand. MycoKeys 56, 13-32. https://doi.org/10.3897/mycokeys.56.35204 (2019).

41. Vadthanarat, S. et al. Two new Erythrophylloporus species (Boletaceae) from Thailand, with two new combinations of American species. MycoKeys 55, 29-57. https://doi.org/10.3897/mycokeys.55.34570 (2019).

42. Vadthanarat, S., Halling, R. E., Amalfi, M., Lumyong, S. \& Raspé, O. An unexpectedly high number of new Sutorius (Boletaceae) species from northern and northeastern Thailand. Front. Microbiol. 12, 643505:1-643505:27. https://doi.org/10.3389/fmicb.2021. 643505 (2021).

43. Sato, H., Tanabe, A. S. \& Toju, H. Contrasting diversity and host association of ectomycorrhizal basidiomycetes versus rootassociated ascomycetes in a dipterocarp rainforest. PLOS ONE 10, e0125550:1-e0125550:20. https://doi.org/10.1371/journal.pone. 0125550 (2015).

44. Peay, K. G. et al. Lack of host specificity leads to independent assortment of dipterocarps and ectomycorrhizal fungi across a soil fertility gradient. Ecol. Lett. 18, 807-816. https://doi.org/10.1111/ele.12459 (2015).

45. Wimolsakcharoen, W., Dumrongrojwatthana, P. \& Trébuil, G. Production of non-timber forest products (NTFPs) and diversity of harvesters' practices and decision-making processes in Northern Thailand community forests. Bois et Forêts des Tropiques 343, 39-52. https://doi.org/10.19182/bft2020.343.a31845 (2020).

46. Chandrasrikul, A. et al. Diversity of Mushrooms and Macrofungi in Thailand (Kasetsart University Press, 2008).

47. Boa, E. R. Wild Edible Fungi: A Global Overview of Their Use and Importance to People; Series on Non-wood Forest Products, No. 17 (Forestry Department, FAO, 2004).

48. Tawatsin, A., Parnmen, S., Thavara, U., Siriyasatien, P. \& Kongtip, P. Mushroom poisoning in Thailand: Incidence and intoxication to human health. Med. Res. Arch. 6, 1-12. https://doi.org/10.18103/mra.v6i9.1847 (2018).

49. Trakulsrichai, S., Jeeratheepatanont, P., Sriapha, C., Tongpoo, A. \& Wananukul, W. Myotoxic mushroom poisoning in Thailand: Clinical characteristics and outcomes. Int. J. Gen. Med. 13, 1139-1146. https://doi.org/10.2147/IJGM.S271914 (2020).

50. Nooron, N. et al. The situation of mushrooms food poisoning in Thailand: Symptoms and common species list. Thai J. Toxicol. 35, 58-69 (2020).

51. Vellinga, E. C. Glossary. In Flora Agaricina Neerlandica, vol. 1 (eds Bas, C., Kuyper, T. W., Noordeloos, M. E. \& Vellinga, E. C.) 54-55 (A.A. Balkema, 1988). ISBN: 9789061918592.

52. Kornerup, A. \& Wanscher, J. H. Methuen Handbook of Colour. (Methuen, 1978). ISBN: 978-0413334008.

53. Clémençon, H. Zwei verbesserte Präparierlösungen für die microskopische Untersuchung von Pilzen. Z. Pilzk. 38, 49-53 (1972).

54. Buyck, B. Valeur taxonomique du bleu de crésyl pour le genre Russula. Bull. Soc. Mycol. Fr. 105, 1-6 (1989).

55. Caboň, M. et al. New insights in Russula subsect. Rubrinae: Phylogeny and the quest for synapomorphic characters. Mycol. Prog. 16, 877-892. https://doi.org/10.1007/s11557-017-1322-0 (2017).

56. Romagnesi, H. Les Russules D'Europe et d'Afrique du Nord. (Bordas, 1967). ISBN: 978-3768213165.

57. Gardes, M. \& Bruns, T. D. ITS primers with enhanced specificity for basidiomycetes-Application to the identification of mycorrhizae and rusts. Mol. Ecol. 2, 113-118. https://doi.org/10.1111/j.1365-294x.1993.tb00005.x (1993).

58. White, T. J., Bruns, T., Lee, S. \& Taylor, J. Amplification and direct sequencing of fungal ribosomal RNA genes for phylogenetics. In PCR Protocols: A Guide to Methods and Applications (eds Innis, M. A. et al.) 315-322 (Academic Press, 1990). https://doi.org/ 10.1016/B978-0-12-372180-8.50042-1.

59. Matheny, P. B. et al. Contributions of $r p b 2$ and tef1 to the phylogeny of mushrooms and allies (Basidiomycota, Fungi). Mol. Phylogenet. Evol. 43, 430-451. https://doi.org/10.1016/j.ympev.2006.08.024 (2007).

60. Kumar, S., Stecher, G., Li, M., Knyaz, C. \& Tamura, K. MEGA X: Molecular Evolutionary Genetic Analysis across computing platforms. Mol. Biol. Evol. 35, 1547-1549. https://doi.org/10.1093/molbev/msy096 (2018).

61. Katoh, K., Rozewicki, J. \& Yamada, K. D. MAFFT online service: Multiple sequence alignment interactive sequence choice and visualization. Brief. Bioinform. 20, 1160-1166. https://doi.org/10.1093/bib/bbx108 (2019).

62. Stamatakis, A. RAxML Version 8: A tool for phylogenetic analysis and post-analysis of large phylogenies. Bioinformatics 30, 1312-1313. https://doi.org/10.1093/bioinformatics/btu033 (2014).

63. Hall, T. A. BioEdit: A user-friendly biological sequence alignment editor and analysis program for Window 95/98/NT. Nucl. Acids Symp. Ser. 41, 95-98 (1999).

64. Darriba, D., Taboada, G. L., Doallo, R. \& Posada, D. jModelTest 2: More models, new heuristics and parallel computing. Nat. Methods 9, 772. https://doi.org/10.1038/nmeth.2109 (2012).

65. Ronquist, F. et al. MrBayes 3.2: Efficient Bayesian phylogenetic inference and model choice across a large model space. Syst. Biol. 61, 539-542. https://doi.org/10.1093/sysbio/sys029 (2012).

66. Rambaut, A., Suchard, M. A., Xie, D. \& Drummond, A. J. Tracer 1.6. Available from: http://beast.bio.ed.ac.uk (2014).

67. Miller, M. A., Pfeiffer, W. \& Schwartz, T. Creating the CIPRES science gateway for inference of large phylogenetic trees. In Proceeding of the Gateway Computing Environments Workshop (GCE) 1-8. https://doi.org/10.1109/GCE.2010.5676129 (2010).

\section{Acknowledgements}

This study was supported by the joint doctorate programme of the Bijzonder Onderzoeksfonds Gent University, Slovak Research and Development Agency (Grant No. APVV-20-0257), DAAD funding programme for ProjectRelated Personal Exchange (PPP; project-ID: 57561196), German Federal Ministry for Education and Research (Grant FunTrAf No. 01DG20015FunTrAf) and National Science Foundation award (DEB-1456588). The authors are very thankful for the kind assistance from Ghent University and Mae Fah Luang University. R. Choeyklin, P. Sawhasan, P. Juthamas, P. Patangwesa and S. Anaphon are acknowledged for their assistance in fieldwork and sample management at BBH. M. Linder and W. Kühlbrandt (Max Planck Institute of Biophysics, Frankfurt am Main) are thanked for the use of scanning electron microscope. S.M.L. Lee (SING herbarium, Singapore) is thanked for providing dried material and ecological data of a specimen of R. bellissima, SL1157.

\section{Author contributions}

K.W., C.M., F.H., T.B., T.T., M.P. and T.A. performed the field work, K.W., C.M. and F.H. observed morhological characters under the microscope, K.W., S.A., A.V. and B.P.L. prepared the concept of the study, K.W. and S.A. wrote the manuscript, A.V., M.C. and B.P.L. gave specific comments to the manuscript, all authors have given approval to the final version of the manuscript. 


\section{Competing interests}

The authors declare no competing interests.

\section{Additional information}

Supplementary Information The online version contains supplementary material available at https://doi.org/ 10.1038/s41598-022-06836-x.

Correspondence and requests for materials should be addressed to S.A.

Reprints and permissions information is available at www.nature.com/reprints.

Publisher's note Springer Nature remains neutral with regard to jurisdictional claims in published maps and institutional affiliations.

(c) (1) Open Access This article is licensed under a Creative Commons Attribution 4.0 International License, which permits use, sharing, adaptation, distribution and reproduction in any medium or format, as long as you give appropriate credit to the original author(s) and the source, provide a link to the Creative Commons licence, and indicate if changes were made. The images or other third party material in this article are included in the article's Creative Commons licence, unless indicated otherwise in a credit line to the material. If material is not included in the article's Creative Commons licence and your intended use is not permitted by statutory regulation or exceeds the permitted use, you will need to obtain permission directly from the copyright holder. To view a copy of this licence, visit http://creativecommons.org/licenses/by/4.0/.

(c) The Author(s) 2022 